\title{
Myxobacterial depsipeptide chondramides interrupt SARS-CoV-2 entry by targeting its broad, cell tropic spike protein: Antagonistic prospects for anti-COVID-19 drug discovery
}

Rey Arturo T. Fernandez ${ }^{\mathrm{a}}$, Mark Tristan J. Quimque, ${ }^{\mathrm{a}, \mathrm{b}}$, Kin Israel R. Notarte ${ }^{\mathrm{c}}$, Joe Anthony H. Manzano $^{\mathrm{d}}$, Delfin Yñigo H. Pilapil ${ }^{\mathrm{d}}$, Von Novi O. de Leon ${ }^{\mathrm{d}}$, John Jeric P. San Jose ${ }^{\mathrm{a}}$, Omar A. Villalobos $^{\mathrm{e}}$, Allan Patrick G. Macabeo ${ }^{\mathrm{a}}$,*

${ }^{a}$ Laboratory for Organic Reactivity, Discovery and Synthesis (LORDS), Research Center for the Natural and Applied Sciences, University of Santo Tomas, España Blvd., Manila1015, Philippines

${ }^{b}$ Chemistry Department, College of Science and Mathematics, Mindanao State University - Iligan Institute of Technology, Tibanga, 9200 Iligan City, Philippines

${ }^{c}$ Faculty of Medicine and Surgery, University of Santo Tomas, España Blvd., Manila 1015, Philippines

${ }^{d}$ Department of Biological Sciences, College of Science, University of Santo Tomas, España Blvd., Manila 1015, Philippines

${ }^{e}$ Department of Pharmacy, Faculty of Pharmacy, University of Santo Tomas, España Blvd., Manila 1015, Philippines

*To whom correspondence should be addressed, e-mail: agmacabeo@ust.edu.ph

\section{Abstract}

The severity of the COVID-19 pandemic necessitated the search for drugs against the causative viral agent, SARS$\mathrm{CoV}-2$. Among the promising targets is the viral surface of SARS-CoV-2 adorned by spike proteins appearing as crown-like structures known for their function in viral attachment and entry mechanisms. To exploit the potential of previously reported antiviral microbial metabolites, we explored the antagonistic prospects of myxobacterial secondary metabolites against receptor-binding domains (RBD) to host cell receptors namely angiotensin-converting enzyme 2 (ACE2), basigin (CD147) and glucose-regulated protein 78 (GRP78) as well as the binding site of neuropilin-1 (NRP1) in the SARS-CoV-2 spike protein using in silico molecular interaction based approaches such as molecular and protein-protein docking along with an investigation of their pharmacokinetic profiles. Thus, the cyclic depsipeptide chondramides in general conferred high affinity and demonstrated strong binding to true viral hot spots in the spike protein such as Arg403, Gln493 and Gln498 with high selectivity compared to most of the host cell receptors studied. The binding energy (BE) of chondramide C3 (1), being the top ligand against ACE2 and CD147 RBD, remained relatively constant when docked against most of the spike variants such as A475V, L452R, V483A, S477N, F490L and V439K. On the other hand, the parent congener chondramide C (2) exhibited strong affinity against the UK variant (N501Y), the South African variant (E484K) and the globally prevalent D614G along with its cooccurring mutation in the RBD, I472V. Meanwhile, chondramide C6 (29) showed highest BE towards GRP78 RBD. To study the effect of complexed chondramide ligands, protein-protein binding experiments were carried out using high-ambiguity driven docking (HADDOCK) which showed weaker binding affinity between spike and the target host receptors. The in silico active chondramides in general conferred favourable pharmacokinetic properties illustrating their potential to be developed as anti-COVID-19 drugs that limit viral attachment and minimize infection.

Keywords: SARS-CoV-2 spike proteins, SARS-CoV-2 variants, COVID-19, molecular docking, protein-protein interaction, viral attachment 


\section{Introduction}

The spike protein crowning SARS-CoV-2, the causative agent of the disease COVID-19 (Ge et al., 2020), is responsible for the initial step of host cell infection. Since the elucidation of its structure, it has been an attractive target and inspiration for drug discovery and vaccine development. The spike is a transmembrane glycoprotein composed of two subunits - the S1 subunit essential for binding to the host cell receptor while the S2 subunit is responsible for viral fusion to host cell membrane (Laurini et al., 2020; Ali \& Vijayan, 2020). The receptor-binding regions of the spike protein is capable of recognizing and attaching to multiple host receptors namely ACE2, CD147, GRP78 and NRP1.

The angiotensin-converting enzyme 2 (ACE2), an enzyme expressed at the outer surface of host cells of lung epithelia, was identified as the critical receptor for mediating SARS-CoV-2 entry (Brielle et al., 2020). The S1 subunit of the spike protein contains a receptor-binding domain (RBD) that is able to recognize ACE2. Within the RBD lies a core and a receptor binding motif; the latter mediating contact with ACE2 (Shang et al., 2020). It has been established that host susceptibility to SARS-CoV-2 is determined by the binding affinity of the spike protein RBD to ACE2 (Walls et al., 2020). Hence, it is critical to consider biologically significant mutations occurring in the RBD that increase pathogenicity. The ACE2 RBD also contains residues that recognize a transmembrane protein that functions as a novel route of SARS-CoV-2 entry. Basigin (CD147) is expressed in activated T cells which can be infected by SARS-CoV-2 in an ACE2-independent manner (Wang et al., 2020). Both ACE2 and CD147 share a similar RBD in the SARS-CoV-2 spike protein.

In proximity to the RBD of the spike to ACE2 lies another region that recognizes a protein called glucose-regulated protein 78 (GRP78). Similar to ACE2, GRP78 is expressed in the respiratory epithelium (Aguiar et al., 2020). Originally found in the lumen of the endoplasmic reticulum, it functions to regulate protein folding, cell death and differentiation (Quinones et al., 2008). GRP78, the master chaperone protein of the unfolded protein response, is overexpressed during cellular stress wherein it escapes endoplasmic reticulum retention and subsequently translocates to the cell membrane (Ibrahim et al., 2019). The protein then becomes susceptible to viral recognition via the RBD of the spike protein to GRP78 (Ibrahim et al., 2020).

In the S1-S2 junction of the spike protein lies an important cleavage site that is proteolytically activated by host cell proteases such as furin (Shang et al., 2020). Subsequently, conformational changes occur in the spike protein which then facilitates viral entry by priming the fusion activity (Cantuti-Castelvetri et al., 2020). Moreover, proteolytic cleavage by furin exposes a conserved $\mathrm{C}$-terminal motif in the spike protein which sequences conform to the $\mathrm{C}$-end rule. Sequences that conform to this rule are able to bind to neuropilin-1 (NRP1), a transmembrane protein important in angiogenesis, axon guidance and is also highly expressed in the olfactory epithelium (Daly et al., 2020). NRP1 has been implicated as a host factor for SARS-CoV-2 infection.

Among the ways to discover antiviral compounds is by tapping natural sources that produce metabolites that exhibit inhibitory properties against viruses. Through the course of evolution, bacteria have developed defensive mechanisms against invading intracellular pathogens (Seed, 2015). The myxobacteria is known to produce structurally and functionally diverse metabolites with broad-spectrum antiviral activity (Mulwa \& Stadler, 2018). Exploiting the 
diversity and evolutionary significance of metabolites produced by myxobacteria is a promising approach in discovering lead structures for drug development (Mohr, 2018).

In this study, we employed in silico techniques to screen antiviral myxobacterial secondary metabolites that may have potential in targeting the receptor-binding domains (RBD) of the SARS-CoV-2 spike protein to angiotensinconverting enzyme 2 (ACE2) and basigin (CD147), glucose-regulated protein 78 (GRP78) RBD and the binding region of neuropilin-1 (NRP1). In this paper, we disclose the in silico myxobacterial chrondramides which exhibited high binding affinities against SARS-CoV-2 spike protein. Protein-protein docking was utilized and selectivity of the top metabolites towards the spike protein was determined to provide further validation of the antagonistic effects towards spike's interaction with various host cell receptors. Additionally, the top-binding chondramides were screened against biologically significant mutations occurring in the RBD of spike to ACE2 namely SARS-CoV-2 variants D164G-I472V, A475V, L452R, V483A, F490L, S477N and N439K. These variants were either reported to exhibit resistance to neutralizing antibodies or demonstrated higher frequencies during the time evolution of SARS-CoV-2 spike RBD mutations indicating stronger transmission capacity. The top hits were also screened against the UK (N501Y) and the South African (E484K) variants. Finally, the pharmacokinetic and toxicity profile of the top hits were determined to investigate druggability of compounds.

\section{Materials and methods}

\section{Ligand selection and preparation}

A library of seventy-two secondary metabolites from the Myxobacteria, previously reported to have properties against HIV, Ebola, Hepatitis C, CMV, and cancer (Mulwa \& Stadler, 2018; Herrmann, Hüttel \& Müller, 2013), were screened against the receptor-binding regions of SARS-CoV-2 spike protein. The structures were converted from SMILES format to SYBYL mol2 file and were optimized using Avogadro (version 1.2.0), an open-source molecular builder. The mol2 files were added to UCSF Chimera platform for docking purposes (Hanwell et al., 2012).

\section{Target protein preparation}

The receptor-binding domains (RBD) of the spike protein crucial for facilitating cellular entry of SARS-CoV-2 were selected as molecular targets. The ACE2 RBD of the spike protein (PDB ID: 6M0J) (Lan et al., 2020) was obtained from the Protein Data Bank (https://www.rcsb.org/) and its crystal structure was added to the UCSF chimera platform (Pettersen et al., 2004). The protein model was prepared by removing all non-standard residues and protein chains and was subsequently minimized by the steepest descent method (100 steps - step size $0.02 \AA$ ) and conjugate gradient method (10 steps - step size $0.02 \AA$ ). Using the same PDB ID, the SARS-CoV-2 variants (N501Y, E484K, A475V, L452R, V483A, F490L, S477N, N439K) were constructed using UCSF chimera platform by editing the necessary amino acids of the spike protein via the swapaa command which utilizes information from a rotomer library (Shapovalov and Dunbrack, 2011). The variants were optimized following the described minimization method. The GRP78 and NRP1 binding regions of spike were prepared similarly using the crystal structure with PDB ID 6VXX (Walls et al., 2020). Modeller (version 9.21) was used to fill in the missing residues of 6VXX (Yang et al., 2012). The residues were re-numbered accordingly by editing the PDB file. The ligands were similarly subjected to molecular 
docking against the following host cell receptors to determine selectivity: ACE2 (PDB ID 6M0J, chain A), CD147 (PDB ID 4U0Q, chain B) and GRP78 (PDB ID 5E84, chain A) (Lan et al., 2020; Wright et al., 2014, Yang et al., 2015).

\section{Molecular docking}

The three-dimensional structures of the proteins derived from RCSB PDB were subsequently used for molecular docking experiments through the UCSF Chimera platform (Pettersen et al., 2004). Minimization and dock-prepping of ligand and protein structures were done by adding the missing hydrogen atoms and appropriate charges to the structures employing the Gasteiger charge method computed using Amber's Antechamber module (Wang et al., 2006). The docking procedure was done using 'flexible ligand into flexible active site' protocol, allowing the ligand's translational and rotational walk within the grid box (Yang et al., 2013). Virtual screening of the prepared library was performed following the Broyden-Fletcher-Goldfarb-Shanoo (BFGS) algorithm of AutoDock Vina (version 1.5.6) with a number of binding modes $=10$ at maximum degree of exhaustiveness (Trott et al., 2010). The binding affinity of the enzyme-ligand complex conformation was determined using UCSF Chimera and was visualized and analysed through BIOVIA Discovery Studios (version 4.1) and ChimeraX platform. Protein-protein docking was done in HADDOCK version 4.2.

\section{Drug-likeness, ADME, and toxicity prediction}

SwissADME software was used to predict absorption, distribution, metabolism and excretion of the hit compounds (Molecular Modeling Group, Swiss Institute of Bioinformatics, 2019). Following Lipinski's rule-of-five, the pharmacokinetic profiles of the compounds that may influence absorption and permeation across cell membranes were evaluated. In order for a compound to exhibit drug likeness, it has to satisfy at least three of the four criteria: molecular weight $<500$ Daltons $(\mathrm{Da})$, calculated lipophilicity $(\log \mathrm{P})<5$, number of hydrogen-bond acceptors $<10$, and number of hydrogen-bond donors $<5$ (Macabeo et al., 2020). In silico toxicity was predicted using OSIRIS property explorer program (Thomas Sander, Idorsia Pharmaceuticals Ltd., 2017) which takes into account the potential mutagenicity, tumorigenicity, irritant effects, and reproductive toxicity of the hit compounds (Phukhamsakda et al., 2018). The solubility (Log S) of the hits was also determined using OSIRIS wherein a Log S value equivalent or greater than -4 is indicative of favorable solubility (Escobedo-González et al., 2017).

\section{Results and discussion}

Molecular docking to Angiotensin-converting enzyme 2 (ACE2) - receptor binding domain (RBD) and SARSCoV-2 spike variants

The main entry of the virus to host cells is through spike binding to ACE2. Key residue substitutions in the C-terminal domain of SARS-CoV-2 strengthened the interaction with ACE2 which led to a higher binding affinity than SARSCoV RBD (Wang et al., 2020). In addition, the ACE2-binding ridge in SARS-CoV-2 RBD has a more compact conformation compared to SARS-CoV (Shang et al., 2020). Furthermore, the SARS-CoV-2 receptor binding motif located in the RBD forms a larger binding interface with more contacts to ACE2 compared with SARS-CoV. Shaping and determining the stability of the protein-protein interface between the spike RBD of SARS-CoV-2 and the ACE2 
receptor, specific residues (Arg403, Gln493, Gln498, Pro499 and Thr500) were identified to be viral hot spots (Laurini et al, 2020; Othman et al, 2020). It is therefore crucial to highlight the intermolecular interactions formed by compounds with viral hot spots for they interfere and potentially disrupt stability of spike binding to ACE2.

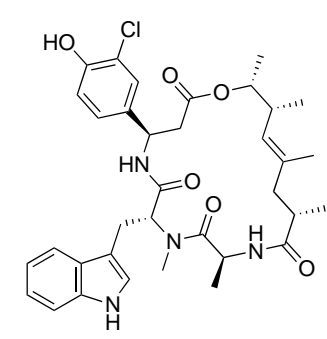

Chondramide C3 (1)

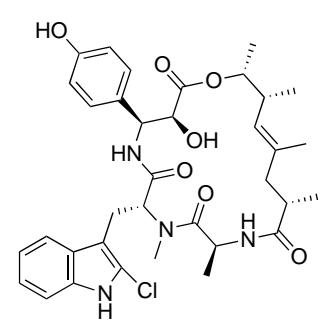

Chondramide E2 (5)

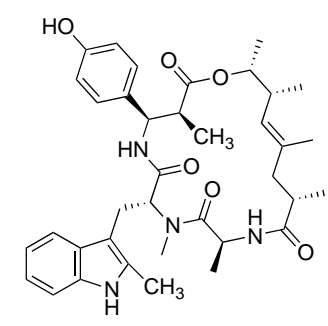

Chondramide C (C1) (2)

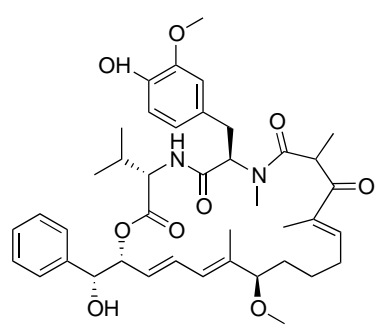

Aetheramide B (6)

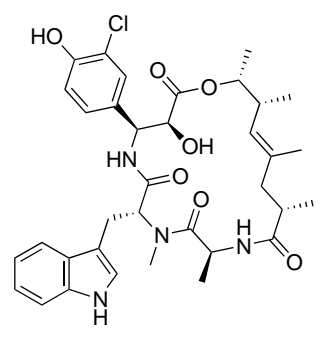

Chondramide E3 (3)

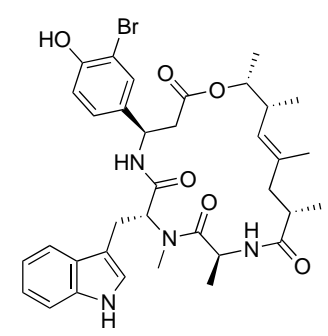

Bromochondramide C3 (7)

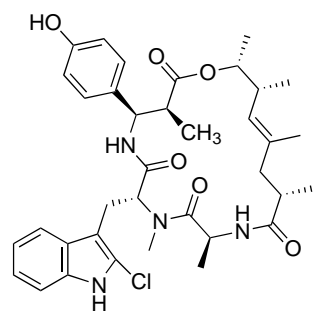

Chondramide D (C2) (4)

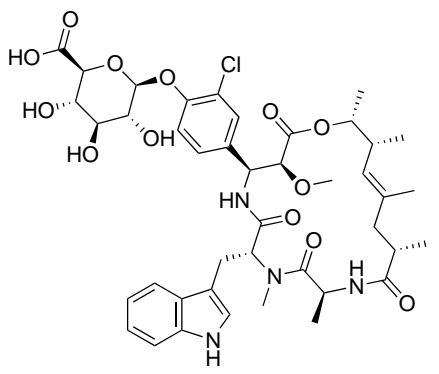

Chondramide A9 (8)

Figure 1. The top scoring compounds (1-8) against spike receptor-binding domain to ACE2.

The top-scoring compounds (Figure 1) are chondramides, cyclic depsipeptides produced by Chondromyces sp. MSr9030 (Herrmann, Hüttel \& Müller, 2013). Chondramide C3 (1) showed the highest affinity to the ACE2 RBD of the viral spike with BE of $-8.7 \mathrm{kcal} / \mathrm{mol}$ (Table 1 ). One of the structural features of $\mathbf{1}$ is a chlorinated phenol moiety (Figure 2). The phenol moiety forms pi-donor bond with Gly496 and conventional hydrogen bonds with Tyr505 and Gly496. Additionally, the indole group is secured through stabilizing interactions against the following amino acid residues of spike RBD: Arg403 (pi-cation), Glu406 (H-bond), Lys417 (pi-alkyl), and Tyr453 (pi-pi stacking). Finally, two more H-bonding were observed: Ser494 against one of the amides and Tyr449 against one of the esters of the macrocyclic chondramide core. Of the viral hot spots in the RBD of the spike, chondramide C3 (1) interacts with Arg403, a true viral hot spot (Laurini et al, 2020). 

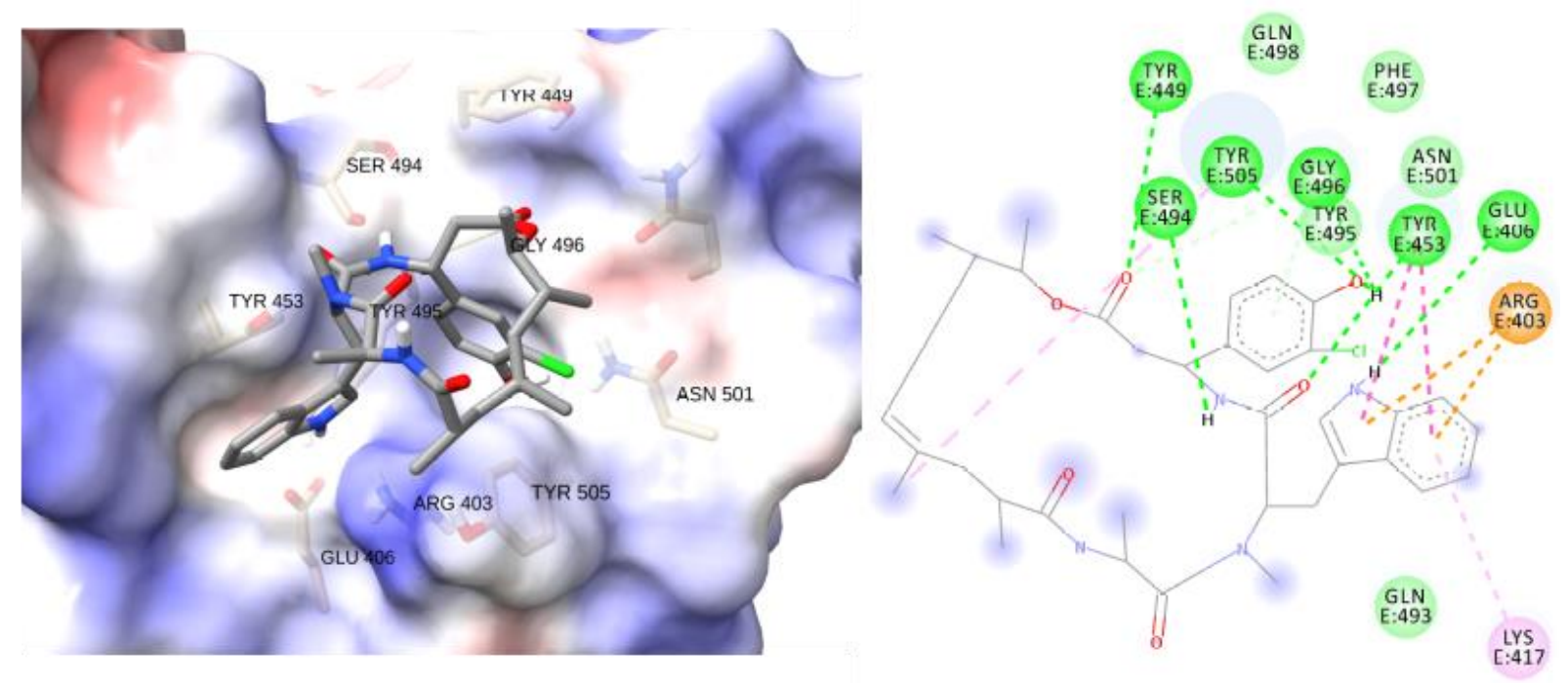

Figure 2. A three-dimensional representation of chondramide C3 (1) showing its position in the receptor-binding domain of spike wild type (left). 2D animated structure showing the binding interactions (right).

It is known from several studies on SARS-CoV that a single amino acid substitution, particularly at spike RBD, affects viral attachment to ACE2 (He \& Jiang, 2006) and overcomes blockade by monoclonal antibodies (Ng et al., 2014). With extended human to human transmission due to the persistence of the pandemic, SARS-CoV-2 may acquire mutations with immunologic resistance and fitness advantage (Korber et al., 2020). Among the SARS-CoV-2 variants, D614G is globally predominant and several studies elucidated its biological significance. D614G is associated with a higher transmission efficacy and a higher case fatality rate (Fernandez 2020; Flores \& Cardozo, 2020). Separately, using Wuhan-1 strain as their template and utilizing the sequences available at the GISAID database, Li and coworkers constructed pseudotyped viruses wherein they documented that single amino acid substitutions in the ACE2 RBD of the viral spike (A475V, L452R, V483A, and F490L) affect the binding of some neutralizing antibodies (Li et al., 2020). The study also revealed that D614G mutation accompanied by a co-occurring single amino substitution in the ACE2 RBD of the spike, I472V, was both resistant to neutralizing antibodies and was more infectious. Meanwhile, spike variants $\mathrm{N} 439 \mathrm{~K}, \mathrm{~S} 477 \mathrm{~N}$ as well as V483A, were identified to occur in higher frequencies during the time evolution of SARS-CoV-2 spike protein RBD which indicates stronger transmission capacity (Chen et al., 2020). Recently, preliminary analysis of the distinct phylogenetic cluster, named lineage B.1.1.7, was observed initially in the United Kingdom wherein it accounts for an increasing proportion of cases in many parts of the world (Rambaut et al., 2020). Dubbed the UK variant, it has been reported to be more infectious and is strongly associated with increasing rates of COVID-19 cases (Wise, 2020). It is noteworthy that among the mutations in the UK variant, mutation N501Y within the RBD, increased binding affinity to human and murine ACE2. On the other hand, emerging lineages in South Africa and Brazil have shown that another variant is responsible for the 10-fold decrease in neutralization by convalescent serum antibodies (Greaney et al., 2020). Characterized with five single-nucleotide variants, the novel lineage B.1.1.28 reveals an E484K mutation located at the RBD (Voloch et al., 2021) previously associated with the escape from neutralizing antibodies (Weisblum et al., 2020) 
Table 1. Summary of the binding energies (BE) and interacting residues of the top chondramides against spike wild-type and variants.

Wild-type

\begin{tabular}{|c|c|c|c|c|c|c|c|c|c|}
\hline \multirow[b]{2}{*}{ Compounds } & \multirow[b]{2}{*}{ BE } & \multicolumn{2}{|r|}{ Wild-type } & \multicolumn{3}{|c|}{ N501Y (UK) } & \multicolumn{3}{|c|}{ E484K (African/Brazil) } \\
\hline & & $\begin{array}{l}\text { Conventional } \\
\text { H-bonding }\end{array}$ & $\begin{array}{c}\text { Other types of molecular } \\
\text { interactions }\end{array}$ & BE & $\begin{array}{l}\text { Conventional } \\
\text { H-bonding }\end{array}$ & $\begin{array}{c}\text { Other types of molecular } \\
\text { interactions }\end{array}$ & $\mathbf{B E}$ & $\begin{array}{l}\text { Conventional } \\
\text { H-bonding }\end{array}$ & $\begin{array}{l}\text { Other types of molecular } \\
\text { interactions }\end{array}$ \\
\hline Chondramide C3 (1) & -8.7 & $\begin{array}{c}\text { Glu406, Tyr449, } \\
\text { Tyr453, Ser494, } \\
\text { Tyr495, Gly496, } \\
\text { Tyr505 }\end{array}$ & $\begin{array}{c}\text { Arg403 ( } \pi \text {-cation), Lys417 ( } \pi \text { - } \\
\text { alkyl), Tyr453 ( } \pi \text { - } \pi \text { stacked), } \\
\text { Tyr505 ( } \pi \text {-alkyl), } \\
\text { Gly496 (C-H bond) }\end{array}$ & -6.6 & $\begin{array}{l}\operatorname{Arg} 403, \text { Ser } 494, \\
\text { Gly496 }\end{array}$ & $\begin{array}{c}\text { Leu455 ( } \pi \text {-alkyl and } \pi \text {-sigma), } \\
\text { Tyr505 ( } \pi \text {-alkyl) }\end{array}$ & -7.2 & Gly496 & $\begin{array}{l}\text { Tyr505 ( } \pi-\pi \text { stacked and } \pi-\pi \mathrm{T}- \\
\text { shaped) } \\
\text { Arg403 (C-H bond), Tyr495 } \\
\text { (Alkyl) }\end{array}$ \\
\hline Chondramide C (2) & -8.6 & Tyr453, Tyr505 & $\begin{array}{c}\text { Tyr449 ( } \pi \text {-alkyl), Tyr505 ( } \pi-\pi \\
\text { stacked, } \pi \text {-alkyl and } \pi-\pi T \text {-shaped) }\end{array}$ & -9.1 & Gly496 & $\begin{array}{l}\text { Tyr449 ( } \pi \text {-alkyl), Tyr501 ( } \pi-\pi \\
\text { stacked),Tyr505 ( } \pi \text { - } \pi T \text {-shaped) }\end{array}$ & -8.7 & $\begin{array}{c}\text { Tyr453, } \\
\text { Asn501, Tyr505 }\end{array}$ & $\begin{array}{l}\text { Tyr449 ( } \pi \text {-alkyl), Tyr505 ( } \pi- \\
\text { alkyl, } \pi-\pi \text { stacked and } \pi-\pi T- \\
\text { shaped) }\end{array}$ \\
\hline Chondramide E3 (3) & -8.4 & $\begin{array}{c}\text { Glu406, Tyr453, } \\
\text { Tyr449, Ser494, } \\
\text { Asn501 }\end{array}$ & $\begin{array}{l}\text { Arg403 ( } \pi \text {-cation), Tyr453 ( } \pi-\pi \\
\text { stacked), Gly496 ( } \pi \text {-donor } \\
\text { hydrogen bond) }\end{array}$ & -7.1 & $\begin{array}{l}\text { Glu406, Ser494, } \\
\text { Gly496 }\end{array}$ & $\begin{array}{c}\text { Tyr453 ( } \pi \text { - } \pi \text { stacked), Leu455 ( } \pi \text { - } \\
\text { sigma), Tyr505 ( } \pi \text {-alkyl) } \\
\text { Arg403 (Unfavourable donor- } \\
\text { donor) }\end{array}$ & -7.5 & Gly496, Gln498 & $\begin{array}{l}\text { Arg403 ( } \pi \text {-cation), Tyr505 ( } \pi \text { - } \pi \\
\text { stacked and } \pi \text {-donor hydrogen } \\
\text { bond) } \\
\text { Gly496 (C-H bond), Asn501 } \\
\text { (Unfavourable donor-donor) }\end{array}$ \\
\hline Chondramide D (4) & -8.4 & $\begin{array}{c}\text { Tyr453, Gly496, } \\
\text { Asn501 }\end{array}$ & $\begin{array}{l}\text { Tyr449 ( } \pi \text {-alkyl), Tyr505 ( } \pi-\pi \\
\text { stacked and } \pi-\pi T \text {-shaped) }\end{array}$ & -8.6 & none & $\begin{array}{c}\text { Tyr449 ( } \pi \text {-alkyl), Tyr501 ( } \pi-\pi \\
\text { stacked), Tyr505 ( } \pi \text { - } \pi \text { T-shaped) } \\
\text { Tyr505 (Unfavourable donor- } \\
\text { donor) }\end{array}$ & -8.4 & Tyr453, Gly496 & $\begin{array}{l}\text { Tyr449 ( } \pi \text {-alkyl), Tyr505 ( } \pi-\pi \\
\text { stacked and } \pi-\pi T \text {-shaped) }\end{array}$ \\
\hline Chondramide E2 (5) & -8.2 & $\begin{array}{l}\text { Tyr449, Gln498, } \\
\text { Asn501 }\end{array}$ & $\begin{array}{c}\text { Tyr449 ( } \pi \text {-alkyl), Tyr505 }(\pi-\pi \\
\text { stacked) } \\
\text { Gly496 (C-H bond })\end{array}$ & -8.6 & Tyr453, Tyr505 & $\begin{array}{l}\text { Tyr449 ( } \pi \text {-alkyl), Tyr501 ( } \pi-\pi \\
\text { stacked), Tyr505 ( } \pi-\pi \text { T-shaped) }\end{array}$ & -8.1 & $\begin{array}{l}\text { Tyr449, Tyr453, } \\
\text { Gln498, Asn501 }\end{array}$ & $\begin{array}{c}\text { Tyr449 ( } \pi \text {-alkyl), Tyr505 }(\pi-\pi \\
\text { stacked) } \\
\text { Gly496 (C-H bond) }\end{array}$ \\
\hline Aetheramide B (6) & -8.1 & $\begin{array}{c}\text { Arg403, } \\
\text { Asn501, Tyr505 }\end{array}$ & $\begin{array}{c}\text { Tyr489 ( } \pi \text { - } \pi \text { T-shaped), Gly496 } \\
\text { ( } \pi \text {-donor hydrogen bond), Tyr505 } \\
\text { ( } \pi-\pi \text { T-shaped) } \\
\text { Lys417 (Alkyl), Asn501 (C-H } \\
\text { bond) }\end{array}$ & -7.2 & $\begin{array}{c}\text { Tyr449, Tyr453, } \\
\text { Gln498 }\end{array}$ & $\begin{array}{r}\text { Tyr449 ( } \pi \text {-alkyl), Tyr495 ( } \pi- \\
\text { sigma), Tyr501 }(\pi \text {-alkyl), Tyr505 } \\
\quad(\pi \text {-alkyl) } \\
\text { Gly446, Ser494 and Tyr501 (C-H } \\
\text { bond })\end{array}$ & -8.1 & Tyr453, Asn501 & $\begin{array}{l}\text { Tyr489 ( } \pi \text { - } \pi \text { T-shaped), Gly496 } \\
\text { ( } \pi \text {-donor hydrogen bond) } \\
\text { Lys417 and Leu455 (Alkyl), } \\
\text { Gly496 and Asn501 (C-H bond) }\end{array}$ \\
\hline $\begin{array}{c}\text { Bromo-chondramide } \mathbf{C} 3 \\
\text { (7) }\end{array}$ & -8.1 & $\begin{array}{l}\text { Tyr453, Gly496, } \\
\text { Asn501, Tyr505 }\end{array}$ & $\begin{array}{c}\text { Tyr505 ( } \pi-\pi \text { stacked and } \pi-\pi \mathrm{T}- \\
\text { shaped })\end{array}$ & -7.5 & Gly496 & $\begin{array}{c}\text { Tyr449, Tyr453 and Tyr495 ( } \pi \text { - } \\
\text { alkyl), Tyr501 ( } \pi-\pi \text { stacked), } \\
\text { Tyr505 ( } \pi-\pi \text { T-shaped })\end{array}$ & -8.1 & $\begin{array}{c}\text { Tyr453, } \\
\text { Asn501, Tyr505 }\end{array}$ & $\begin{array}{c}\text { Tyr505 ( } \pi-\pi \text { stacked and } \pi-\pi \text { T- } \\
\text { shaped })\end{array}$ \\
\hline Chondramide A9 (8) & -8 & Tyr449, Ser494 & $\begin{array}{c}\text { Tyr449 ( } \pi-\pi \text { stacked), Tyr505 ( } \pi- \\
\text { alkyl) } \\
\text { Tyr495 and Gly496 (C-H bond), } \\
\text { Gln493 (Unfavourable donor- } \\
\text { donor) }\end{array}$ & -8.6 & $\begin{array}{c}\operatorname{Arg} 403, \\
\text { Gln } 409, \\
\text { Lys417, Gly496 }\end{array}$ & $\begin{array}{c}\operatorname{Arg} 403 \text { ( } \pi \text {-cation), Tyr453 ( } \pi \text { - } \pi \\
\text { stacked), Leu455 ( } \pi \text {-sigma) } \\
\text { Tyr501 (C-H bond) }\end{array}$ & -7.9 & Ser349, Asn450 & $\begin{array}{c}\text { Tyr449 and Leu452 ( } \pi \text {-alkyl) } \\
\text { Phe347 and Ser349 } \\
\text { (Unfavourable donor-donor), } \\
\text { Asn } 450 \text { (C-H bond) }\end{array}$ \\
\hline
\end{tabular}


Table 1 cont.

\section{D614G-I472V}

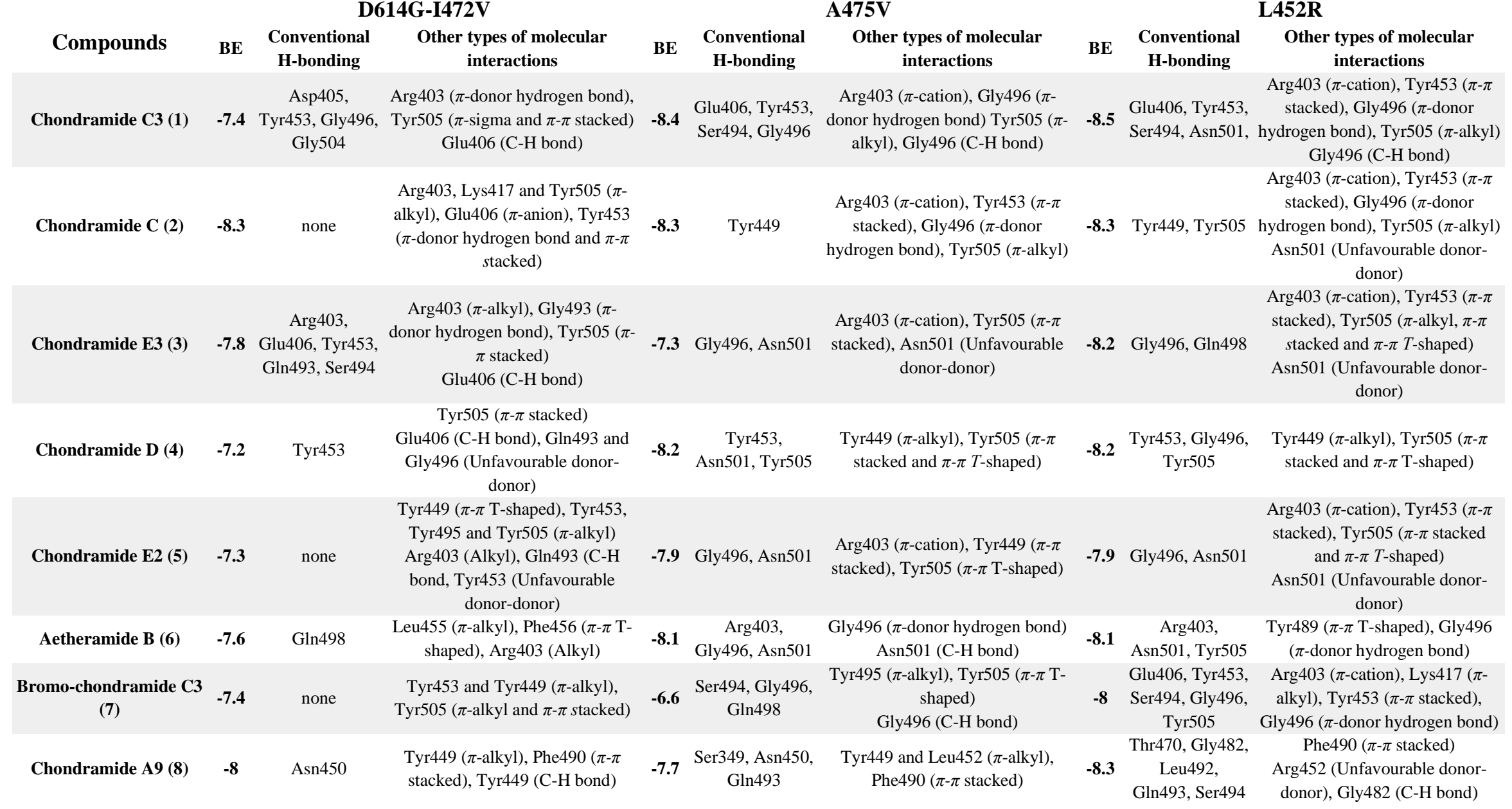


Table 1 cont.

V483A

Cpd BE Conventional H-bonding

Glu406,

Tyr453,

Ser494,

Asn501

Tyr453,

$2 \quad \mathbf{8 . 4}$ Asn501

Tyr505

$\begin{array}{llll} & & & \operatorname{Arg} 403 \text { ( } \pi \text {-cation }), T y r 453 \\ (\pi-\pi \text { stacked), Tyr505 ( } \pi-\pi\end{array}$

$\pi-\pi$ stacked), Tyr505 (
stacked and $\pi$-alkyl)

Tyr449 ( $\pi$-alkyl), Tyr505

$(\pi-\pi$ T-shaped and $\pi$-alkyl)

Tyr449 ( $\pi$-alkyl), Tyr505

( $\pi-\pi$ stacked and $\pi-\pi T$ -

$$
\text { shaped) }
$$

Arg403 ( $\pi$-cation), Tyr453

$(\pi-\pi$ stacked), Tyr505 ( $\pi-\pi$

stacked and $\pi-\pi T$-shaped)

Asn501 (Unfavourable)

Tyr489 ( $\pi-\pi$ T-shaped),

$\begin{array}{rrrr}\text { 6rg } 403, & \begin{array}{r}\text { Gly496 ( } \pi \text {-donor hydrogen } \\ \text { bond), Tyr505 ( } \pi \text {-alkyl), }\end{array}\end{array}$

Gly496 (C-H bond)

Ser494, Tyr505 ( $\pi-\pi$ T-shaped and

$7 \quad \mathbf{- 7 . 8}$ Gly 496 ,

$\pi$-alkyl)

Gly496 (C-H bond)

Gln498

Tyr449 and Leu452 ( $\pi$ -

$8 \quad \mathbf{8 . 2} \quad$ Asn 450 , alkyl), Ser349 Gln493 (Unfavourable), Tyr449 (C- ${ }^{-7.6}$ Gln493, $\mathrm{H}$ bond)
Tyr449

F490L

\section{Conventional \\ Other types of \\ molecular interactions \\ BE Conventional}

$\operatorname{Arg} 403$ ( $\pi$-cation),

Glu406,

Tyr453,

Ser494,

Asn501

Tyr453 ( $\pi-\pi$ stacked $)$

Gly496 ( $\pi$-donor

hydrogen bond), Tyr505

( $\pi$-alkyl), Gly496 (C-H

$$
\text { bond) }
$$

$\operatorname{Arg} 403$ ( $\pi$-cation),

Tyr453 ( $\pi-\pi$ stacked)

Gly496 ( $\pi$-donor

hydrogen bond), Tyr505

$$
\text { ( } \pi \text {-alkyl) }
$$

$\operatorname{Arg} 403$ ( $\pi$-cation),

Tyr453 ( $\pi-\pi$ stacked),

Tyr505 ( $\pi-\pi$ stacked and

$\pi-\pi T$-shaped), Asn501

(Unfavourable donor-

$$
\text { donor) }
$$

Tyr449 ( $\pi$-alkyl), Tyr505

( $\pi-\pi$ stacked and $\pi-\pi$ T-

$$
\text { shaped) }
$$

$\operatorname{Arg} 403$ ( $\pi$-cation),

Tyr453 ( $\pi-\pi$ stacked),

Tyr505 ( $\pi-\pi$ stacked and $\quad \mathbf{- 7 . 9} \quad$ Gly496

$\pi-\pi T$-shaped), Asn501

(Unfavourable)

Tyr489 ( $\pi-\pi$ T-shaped),

Gly496 ( $\pi$-donor

hydrogen bond), Gly496

and Asn501 (C-H bond)

Tyr505 ( $\pi$-alkyl and $\pi$ - $\pi$

$$
\text { T-shaped) }
$$

Gly496 (C-H bond)

Tyr505 ( $\pi$-alkyl)

Gly493 and Ser 494

(Unfavourable), Tyr495

and Gly496 (C-H bond)

H-bonding

Glu406,

Tyr453,

Ser494,

Gly496,

Tyr505

Tyr453,

Asn501

Arg403,

8.1 Gly496,

Asn501

Tyr453,

-7.8 Asn501,

Tyr505

$\begin{array}{ll}\text {-7.7 Ser494, } & \text { Gln498 }\end{array}$

\section{S477N}

-8.4 Gly496,

Tyr449 ( $\pi$-alkyl), Tyr505 ( $\pi-\pi$ T-

shaped and $\pi$-alkyl)

-8.3 Tyr449, Tyr505

types of mole

Arg403 ( $\pi$-cation), Lys417 ( $\pi$ -

aklyl), Tyr453 ( $\pi-\pi$ stacked),

Gly496 ( $\pi$-donor hydrogen

bond), Tyr505 ( $\pi$-alkyl), Gly496 (C-H bond)

$\operatorname{Arg} 403$ ( $\pi$-cation), Tyr505 ( $\pi$ - $\pi$ donor-donor)

Gln498

Tyr449 ( $\pi$-alkyl), Tyr505 ( $\pi-\pi$

stacked and $\pi-\pi T$-shaped)

$\operatorname{Arg} 403$

Arg403 ( $\pi$-cation), Tyr453 ( $\pi-\pi$

stacked), Tyr505 ( $\pi-\pi$ stacked

$$
\text { and } \pi-\pi T \text {-shaped) }
$$

Gln498 and Asn501

(Unfavourable)

Arg403 ( $\pi$-cation), Lys417

(Alkyl), Tyr489 ( $\pi$-alkyl) shaped)

$\begin{array}{cc}\text { Tyr505 ( } \pi \text {-alkyl) } & \text { Phe347 } \\ \text { Gly493 and Ser 494 } & \text { Ser349 }\end{array}$

$\begin{array}{cc}\text { Tyr505 ( } \pi \text {-alkyl) } & \text { Phe347 } \\ \text { Gly493 and Ser 494 } & \text { Ser349 }\end{array}$

bond)
Tyr505 ( $\pi-\pi$ stacked and $\pi-\pi T-$

\section{N439K}

Other types of molecular interactions

$\operatorname{Arg} 403$ ( $\pi$-cation), Tyr453 ( $\pi-\pi$ stacked), Gly496 ( $\pi$-donor hydrogen bond), Tyr505 ( $\pi$-alkyl) Gly496 (C-H bond)

$\operatorname{Arg} 403$ ( $\pi$-cation), Tyr453 ( $\pi-\pi$ stacked), Gly496 ( $\pi$-donor

hydrogen bond), Tyr505 ( $\pi$-alkyl) Gly496 (C-H bond)

Arg403 ( $\pi$-cation), Tyr505 ( $\pi-\pi$ stacked), Asn501 (Unfavourable donor-donor)

Tyr449 ( $\pi$-alkyl), Tyr505 ( $\pi-\pi$

stacked and $\pi-\pi T$-shaped)

$\operatorname{Arg} 403$ ( $\pi$-cation), Tyr453 ( $\pi-\pi$ stacked), Tyr505 ( $\pi$ - $\pi$ stacked and $\pi-\pi T$-shaped)

Gln498 and Asn50 (Unfavourable)

Lys417 ( $\pi$-alkyl), Tyr489 ( $\pi-\pi$ Tshaped)

Gly496 (C-H bond)

Tyr505 ( $\pi$ - $\pi$ T-shaped and $\pi$-alkyl) Gly496 (C-H bond)

Tyr449 and Leu452 ( $\pi$-alkyl) 
Due to the clinical relevance of mutations, it is essential to likewise screen for compounds with high affinity to variants of the spike protein. Hence, in silico analysis of the top chondramide was performed to SARS-CoV-2 spike variants. We docked the top ligand, chondramide C3 (1), to see whether the mutations affect binding affinity. Across all variants, the binding affinity of 1 remained constant except towards UK variant N501Y (-6.6 kcal/mol), African variant E484K (-7.2 kcal/mol) and D614G-I472V (-7.4 kcal/mol) wherein a drop in the BE was observed (Table 1). Based on post-docking analysis of compound $\mathbf{1}$ against N501Y, the new residue (Tyr501) did not exhibit a significant non-van der Waal's interaction with the ligand (Figure 3). The same can be said with compound 1's attachment to E484K, where the replaced residue Lys484 did not participate in the ligand's attachment. The point mutations on the aforementioned variants are of the non-conservative type which may have resulted in a change in the binding properties of RBD (Figure 4). The swap to more polar residues capable of hydrogen bonding, as in the case of N501Y and $\mathrm{E} 484 \mathrm{~K}$, creates a more polar environment on the receptors which may consequently promote the accommodation of more polar ligands compared to the wild type. One of the major structural features of chondramide C3 (1) is an ortho-chloro substituent on the phenol moiety. The presence of an electronegative substituent, such as chlorine, on phenol hinders intermolecular hydrogen bonding (against certain polar residues) due to the participation of the hydroxyl group in H-bonding with the ortho substituent intramolecularly, which in turn affects the polarity of the compound. To further explore this observed relationship between the polarity of ligands and the spike variants, we subjected other top metabolites (against wildtype spike) to molecular docking against the different variants. Among them, chondramide C (2) revealed strong affinity against N501Y (-9.1 kcal/mol), E484K (-8.7 kcal/mol) and D614G$\mathrm{I} 472 \mathrm{~V}(-8.3 \mathrm{kcal} / \mathrm{mol})$. Structurally, one of the major differences between compounds $\mathbf{1}$ and $\mathbf{2}$ is the absence of an ortho-chloro substituent in the phenol moiety of the latter. Post-docking analysis of compound 2 against N501Y revealed the presence of a conventional hydrogen bonding between phenol and Gly496 and stacked pi-pi interactions between the indole moiety and Tyr501 and Tyr505. In the case of 2's attachment to E484K, three prominent hydrogen bonding can be observed on the phenol moiety (against Asn501 and Tyr505) and the ester group (against 453).
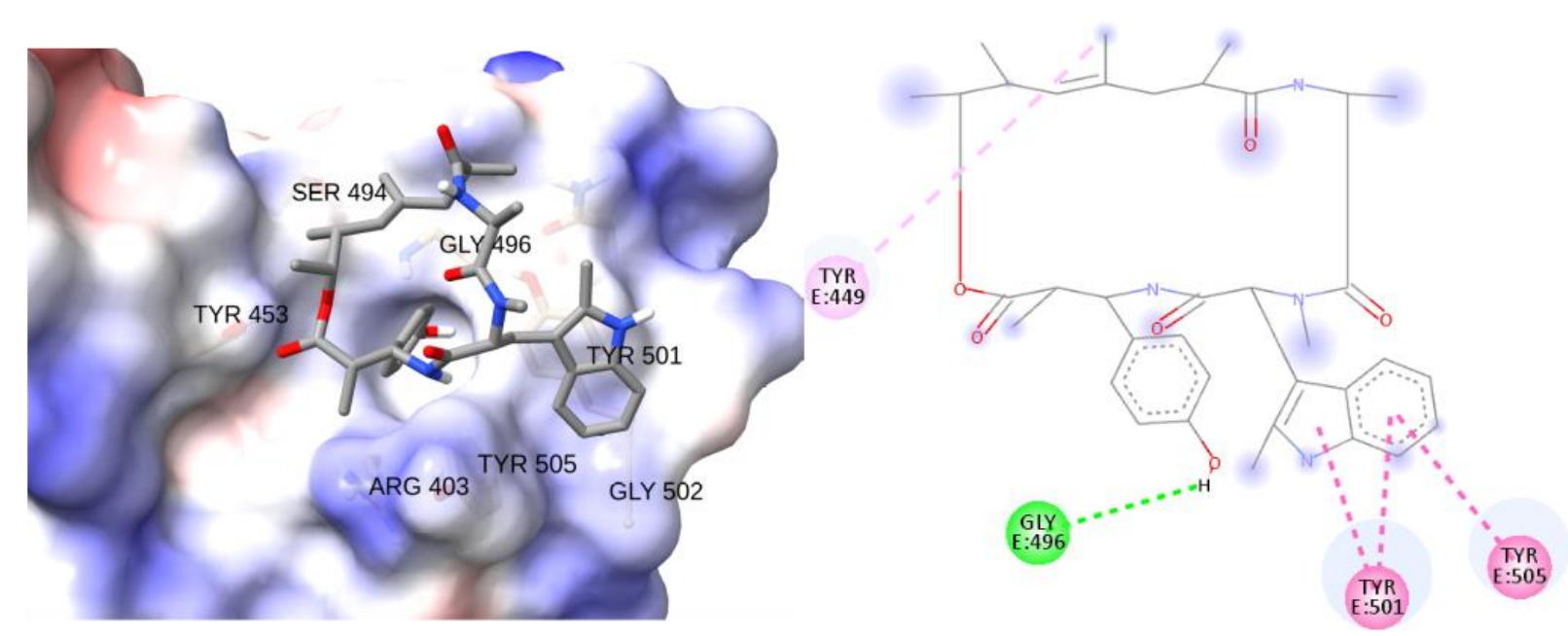

Figure 3. A three-dimensional representation of chondramide C (2) showing its position in the receptor-binding domain of UK variant N501Y (left). 2D animated structure showing the binding interactions (right). 

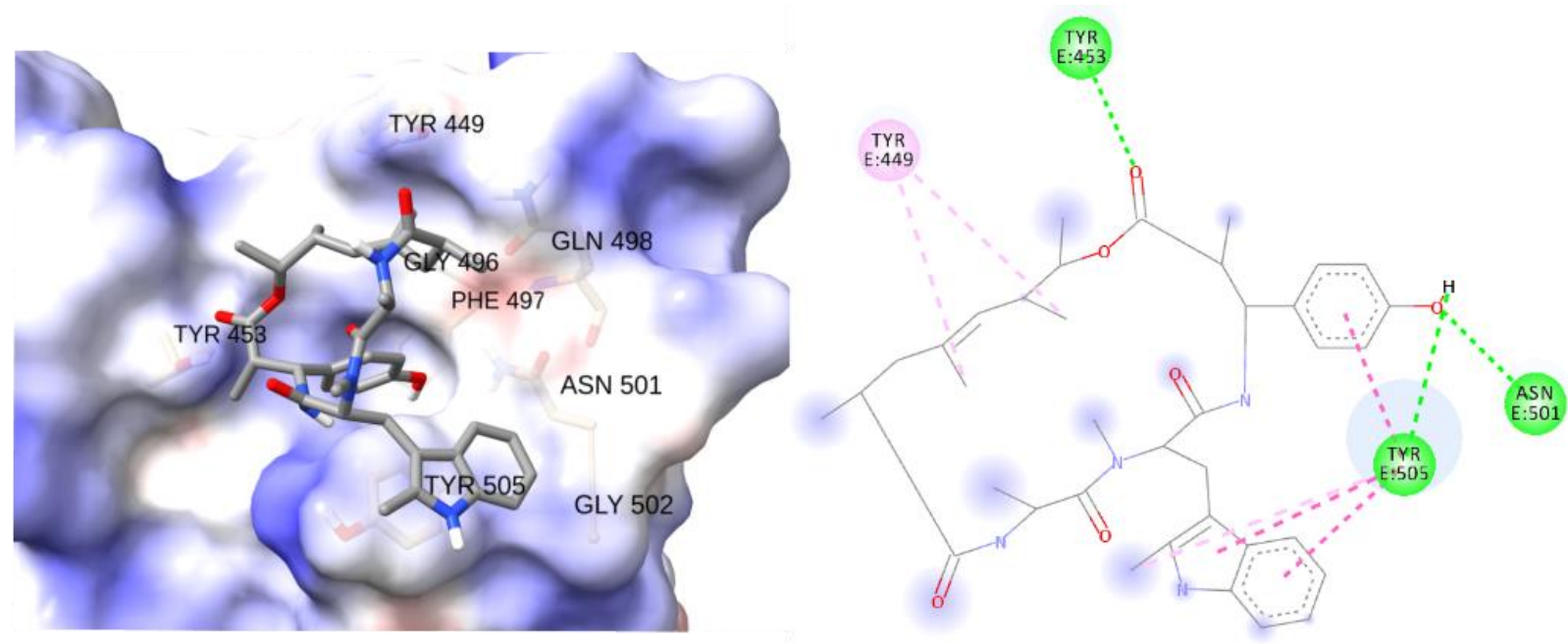

Figure 4. A three-dimensional representation of chondramide $C$ (2) showing its position in the receptor-binding domain of South African variant E484K (left). 2D animated structure showing the binding interactions (right).

Other metabolites that exhibited an increase in binding affinity towards N501Y, compared to the wildtype, are chondramides D (4), E2 (5), and A9 (8). Similar to 2, compound 4 does not have an ortho-chlorine on the phenol group. Compounds $\mathbf{5}$ and $\mathbf{8}$, on the other hand, fashion a hydroxyl substituent alpha to the ester and a glycosylated phenol, respectively. These data support our observation that having a free (no ortho substituent) phenol and/or further oxidation of the chondramide core would increase binding to certain RBD variants, particularly those with nonconservative mutations like $\mathrm{N} 501 \mathrm{Y}$ and $\mathrm{E} 484 \mathrm{~K}$ where their binding receptor environment is made more polar.

\section{Molecular docking to CD147 - receptor binding domain (RBD)}

CD147 is a transmembrane glycoprotein that belongs to the immunoglobulin superfamily (Muramatsu, 2016). It is involved in the regulation of immune responses with its expression strongly associated with activated lymphocytes. It has been speculated that due to the high infectivity of SARS-CoV-2, ACE2 might not be the only route of host cell entry. It turns out that CD147 is another route of SARS-CoV-2 viral entry (Wang et al., 2020). Since CD147 is associated with activated lymphocytes, one might reason that lymphocytes are relatively abundant in COVID-19 afflicted patients which may explain the high infectivity rates seen in SARS-CoV-2. However, lymphopenia with characteristic decline in $\mathrm{T}$ cell counts, is a particular finding in patients with COVID-19 predicting disease severity (Chen et al., 2020; Huang et al., 2020; Liu et al., 2020). A convincing explanation to COVID-19 associated lymphopenia is infection of $\mathrm{T}$ cells by SARS-CoV-2. As highlighted as one of the possible mechanisms of lymphopenia in patients with COVID-19 (Jafarzadeh et al., 2020), lymphocytes can be infected by SARS-CoV-2 in an ACE2-independent manner through the transmembrane receptor CD147 (Wang et al., 2020) and can potentially induce apoptosis in lymphocytes (Xiong et al., 2020). CD147 enables viral entry through endocytosis and is inhibited by blocking CD147 through Meplazumab, an anti-CD147 antibody (Wang et al., 2020).

SARS-CoV-2 spike interacts with CD147 through similar binding residues responsible for ACE2 recognition. The spike external subdomain in the grove between the short antiparallel $b$ strands b1' and b2' and the small helix a1' comes into contact with the C-terminal domain of CD147 (Helal et al., 2020). Among the multiple interacting residues 
located in the spike protein, residues Arg403, Tyr449, Asn481, Val483, and Tyr505 contributed significantly to CD147 attachment. We observed that chondramide C3 (1) formed intermolecular interactions with two of the five key residues for CD147 namely Arg403 and Tyr505 via pi-cation and pi-alkyl, respectively.

As discussed previously, lymphopenia predicts disease severity in patients with COVID-19. Severe disease is also associated in patients with co-morbidities such as chronic obstructive pulmonary disease (COPD), asthma, obesity and hypertension. The molecular mechanism behind the association of COVID-19 severity and the above-mentioned co-morbidities is presented by the study of Radzikowska et al. wherein CD147 and related genes were highly expressed (Radzikowska et al., 2020). Given that CD147 is highly expressed in co-morbidities and is the route of SARS-CoV-2 infection in T cells, blocking the RBD of spike protein to CD147 will potentially inhibit viral entry into $\mathrm{T}$ cells thereby reducing the risk of lymphopenia - a characteristic marker of disease severity.

\section{Molecular docking to Glucose-regulated protein 78 (GRP78) - receptor binding domain (RBD)}

SARS-CoV-2 spike binding to GRP78 is an alternative way of viral entry to host cells. Elevated during cellular stress, it translocates from the endoplasmic reticulum to the cell membrane wherein it becomes susceptible to viral recognition (Ibrahim et al., 2020). GRP78 was significantly elevated in the serum of SARS-CoV-2 positive patients compared to COVID-19 negative pneumonia and control group (Sabirli et al., 2020) and has been investigated as a potential therapeutic target (Allam et al., 2020; Palmeria et al., 2020).

The binding site of SARS-CoV-2 spike protein to GRP78 is located in between regions III and IV wherein the latter is the main driver for binding as predicted in silico (Ibrahim et al., 2020). Consistently, the top-scoring compounds belong to the chondramide family of secondary metabolites produced by Chondromyces sp. MSr9030 (Herrmann, Hüttel \& Müller, 2013). Chondramide C6 (29) displayed the highest affinity against the GRP78-binding region of spike with the binding energy of $-8.8 \mathrm{kcal} / \mathrm{mol}$. The presence of a phosphorylated phenol on 29 helped stabilize the compound's attachment to the binding region through hydrogen binding with Asn506 (Figure 5). Another H-bonding is also observed between the adjacent amide group and Gly495. Moreover, the indole moiety is involved in pi-anion and pi-sigma interactions with Asp486 and Leu474, respectively. Both aromatic groups are also in contact with Pro510 via pi-alkyl interplay. 

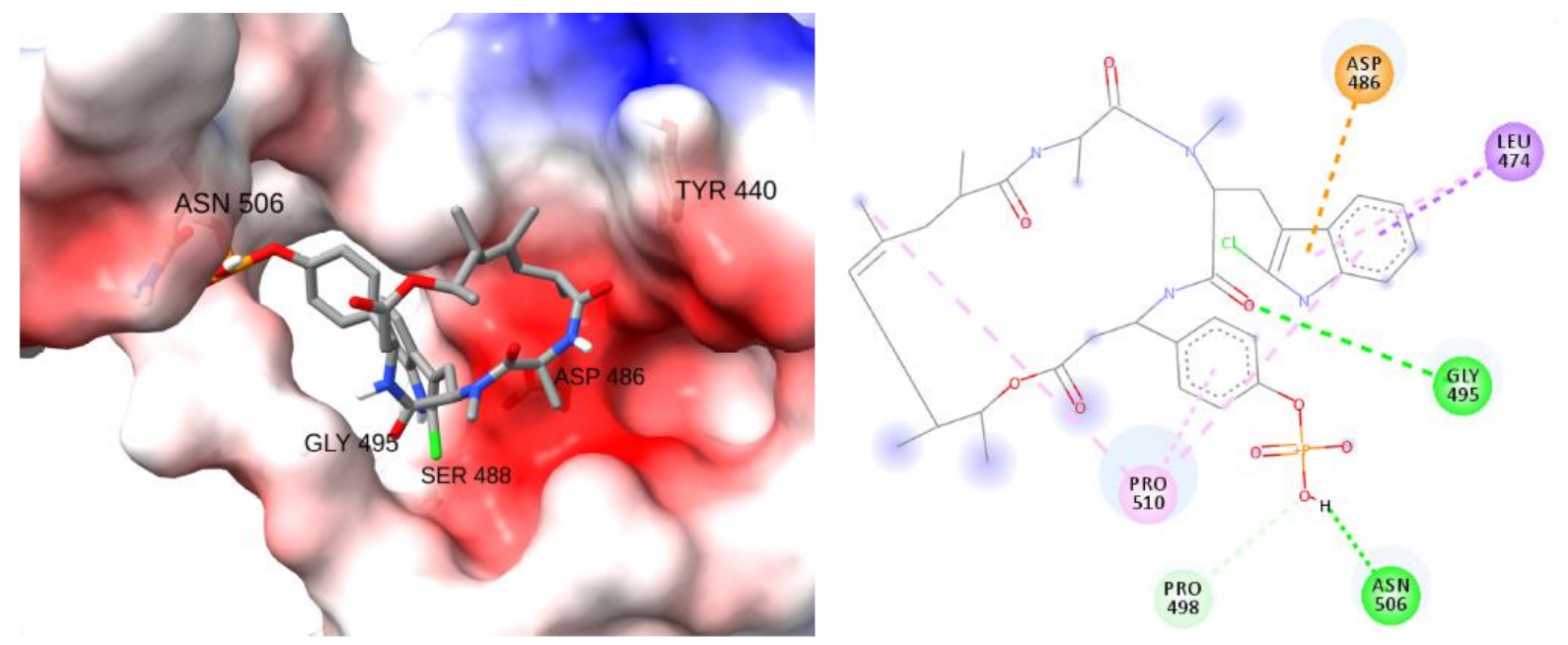

Figure 5. A three-dimensional representation of chondramide $C$ (2) showing its position in the receptor-binding domain of GRP78 (left). 2D animated structure showing the binding interactions (right).

\section{Molecular docking to Neuropilin-1 (NRP1) receptor-binding site in SARS-CoV-2 spike protein}

NRP1 is a transmembrane protein involved in angiogenesis and axon guidance which has been identified as a host factor for SARS-CoV-2 infection (Daly et al., 2020) wherein it facilitates viral entry and infectivity (CantutiCastelvetri et al., 2020). SARS-CoV-2 entry is facilitated by proteolytic cleavage through furin subsequently exposing a conserved C-terminal motif in the spike protein. The outcome after cleave is a sequence conforming to a C-end peptide rule that is recognized by NRP1. Our docking studies demonstrate low binding affinities of myxobacterial metabolites against the NRP1 binding site in the spike protein.

\section{Protein-protein and selectivity docking}

Aside from investigating the attachment of chondramides towards different receptor-binding domains of spike, we would want to look at the effect of the bound ligand to the binding behaviour of spike against the host receptor proteins. Protein-protein docking was performed between spike, with and without the top-binding ligand, versus ACE2, GRP78 and CD147.

The spike RBD and ACE2 protein complex demonstrated a strong binding affinity (HADDOCK score) of -130.9 \pm 0.2 . On the other hand, the attachment of chondramide C3 (1) onto spike RBD resulted in a weaker affinity towards ACE2 as exhibited by a decrease in HADDOCK score at $-82.1 \pm 6.3$. A similar observation was also evident between spike-GRP78 and spike-CD147 complexes where the presence of chondramides C6 (29) and C3 (1), respectively, hindered the formation of stable complexes. The bound chondramide $\mathbf{2 9}$ at the interspace between spike RBD and GRP78 resulted in a decline in a HADDOCK score by about 37.3. Meanwhile, the bound chondramide 1 impeded the adjoining of spike RBD and CD147 as demonstrated by a decrease in HADDOCK score from $-122.4 \pm 3.6$ to $-82.5 \pm$ 6.4. Through protein-protein docking, we were able to further demonstrate the potential antagonistic effects of chondramides 1 and $\mathbf{2 9}$ against the spike protein RBD's attachment to ACE2, GRP78 and CD147. 
Selectivity docking also demonstrated when 1 showed a lower BE when docked against ACE2 $(-6.1 \mathrm{kcal} / \mathrm{mol})$ and CD147 $(-7.5 \mathrm{kcal} / \mathrm{mol})$ which highlights its selectivity towards the RBD of the spike protein $(-8.7 \mathrm{kcal} / \mathrm{mol})$. Chondramide $C$ revealed selectivity towards the variants of the spike protein (UK variant: $-9.1 \mathrm{kcal} / \mathrm{mol}$; African variant: $-8.7 \mathrm{kcal} / \mathrm{mol}$; D614G-I472V: $-8.3 \mathrm{kcal} / \mathrm{mol})$ compared when docked to ACE2 $(-7.0 \mathrm{kcal} / \mathrm{mol})$. Finally, chondramide C6 was also selective towards the RBD of the spike protein $(-8.8 \mathrm{kcal} / \mathrm{mol})$ versus GRP78 $(-6.8$ $\mathrm{kcal} / \mathrm{mol})$.

\section{In silico ADMET and drug-likeness}

The pharmacokinetic properties of the top-scoring compounds were predicted using Swiss ADME (Daina et al., 2017). Based on the Lipinski's Rule of Five, the drug-likeness of the compounds was assessed by looking into their chemical properties, such as molecular weight, lipophilicity (reported as octanol-water partition coefficient), and the number of hydrogen bond donors and acceptors (Table 2) Among the top-scoring chondramides and their derivatives with high binding energy to the SARS-CoV2 spikes, compounds 1, 2, 4, 6 and 7 were highly druggable as reflected by their favorable ADME (absorption, distribution, metabolism and excretion) characteristics. Despite the computation that the top-scoring compounds $\mathbf{3}, \mathbf{5}$, and $\mathbf{8}$ were non-druggable according to Lipinski's rule of five, successful drug candidates could be under the extended or beyond the rule of five domain of oral availability considering the abundance of binding site hot spots that are filled by larger candidates and thereby improve affinity or selectivity (Egbert et al., 2019).

Table 2. Lipinski's Rule of Five for ADME analysis of compounds 1-8.

\begin{tabular}{ccccccc}
\hline Cpd & $\begin{array}{c}\text { MW } \\
(<\mathbf{5 0 0})\end{array}$ & $\begin{array}{c}\text { \#H-bond } \\
\text { acceptors }(<\mathbf{1 0})\end{array}$ & $\begin{array}{c}\text { \#H-bond } \\
\text { donors }(<\mathbf{5})\end{array}$ & MLOGP $(<\mathbf{5})$ & $\begin{array}{c}\text { Lipinski } \\
\text { \#violations }\end{array}$ & $\begin{array}{c}\text { Drug } \\
\text { Likeness }\end{array}$ \\
\hline $\mathbf{1}$ & 651.19 & 6 & 4 & 2.45 & 1 & YES \\
$\mathbf{2}$ & 616.75 & 6 & 4 & 2 & 1 & YES \\
$\mathbf{3}$ & 667.19 & 7 & 5 & 1.68 & 2 & NO \\
$\mathbf{4}$ & 651.19 & 6 & 4 & 2.45 & 1 & YES \\
$\mathbf{5}$ & 667.19 & 7 & 5 & & & NO \\
$\mathbf{6}$ & 718.88 & 9 & 3 & 1.68 & 2 & YES \\
$\mathbf{7}$ & 695.64 & 6 & 4 & 2.53 & 1 & YES \\
$\mathbf{8}$ & 857.34 & 13 & 7 & -0.41 & 3 & NO \\
\hline
\end{tabular}

In addition, the mutagenicity, tumorigenicity, irritant effect and reproductive toxicity of the top-scoring compounds were also evaluated using OSIRIS Property Explorer (Quimque, 2020). The toxicity risks of the compounds are presented in Table 3. Among the top-scoring chondramide group of secondary metabolites, compounds 
$1,2,3,4,5,7$ and 8 did not exhibit any form of toxicity. Taking into consideration both drug-likeness and in silico toxicity, chondramide C3 (1) and chondramide C (2) exemplified the most promising pharmacokinetic characteristics.

Table 3. Predicted toxicity parameters and solubility of compounds 1-8.

\begin{tabular}{ccccc} 
& \multicolumn{4}{c}{ Toxicity Risks } \\
\cline { 2 - 5 } & Mutagenicity & Tumorigenicity & Irritant effect & Reproductive toxicity \\
\hline $\mathbf{1}$ & None & None & None & None \\
$\mathbf{2}$ & None & None & None & None \\
$\mathbf{3}$ & None & None & None & None \\
$\mathbf{4}$ & None & None & None & None \\
$\mathbf{5}$ & None & None & None & None \\
$\mathbf{6}$ & None & None & Medium-risk & None \\
$\mathbf{7}$ & None & None & None & None \\
$\mathbf{8}$ & None & None & None & None \\
\hline
\end{tabular}

\section{Conclusion}

In the face of this pandemic, we strive to discover treatment options for patients afflicted with COVID-19. Natural products have been and continue to be an important source of antivirals in the pharmaceutical industry. Through our study, we explored the role of myxobacterial metabolites' antagonistic prospects and revealed their potential use as drug candidates against multiple mechanisms of viral entry by targeting receptor-binding domains (RBD) to ACE2/CD147 and GRP78. Furthermore, we demonstrated binding of these compounds to known hot spots in the spike protein. We documented the importance of screening compounds against variants of the spike and we highlight the polar environment influenced by N501Y and E484K promoted affinity of more polar ligands compared to the wildtype. Finally, chondramides C3 (1), C (2) and C6 (29) did not only exhibit high binding scores but were effective in hindering the attachment of SARS-CoV-2 spike protein towards target host receptors as observed in the proteinprotein docking analysis. In summary, we provide a strong basis to pursue in vitro experiments for anti-COVID-19 drugs as well as an inspiration for future studies in antiviral drug discovery.

\section{Conflicts of interest}

There are no conflicts to declare.

\section{References}


1 H. Ge, X. Wang, X. Yuan, G. Xiao, C. Wang, T. Deng, Q. Yuan and X. Xiao, The epidemiology and clinical information about COVID-19, Eur. J. Clin. Microbiol. Infect. Dis., 2020, 39, 1011-1019.

2 E. Laurini, D. Marson, S. Aulic, M. Fermeglia and S. Pricl, Computational alanine scanning and structural analysis of the SARS-CoV-2 spike protein/angiotensin-converting enzyme 2 complex, ACS Nano, 2020, 14, $11821-11830$.

3 A. Ali and R. Vijayan, Dynamics of the ACE2-SARS-CoV-2/SARS-CoV spike protein interface reveal unique mechanisms, Sci. Rep., 2020, 10, 1-12.

4 E. S. Brielle, D. Schneidman-Duhovny and M. Linial, The SARS-CoV-2 exerts a distinctive strategy for interacting with the ACE2 human receptor, Viruses, 2020, 12, 497.

5 J. Shang, G. Ye, K. Shi, Y. Wan, C. Luo, H. Aihara, Q. Geng, A. Auerbach and F. Li, Structural basis of receptor recognition by SARS-CoV-2, Nature, 2020, 581, 221-224.

6 A. C. Walls, Y. J. Park, M. A. Tortorici, A. Wall, A. T. McGuire and D. Veesler, Structure, function, and antigenicity of the SARS-CoV-2 spike glycoprotein, Cell, 2020, 181, 281-292.e6.

7 K. Wang, W. Chen, Z. Zhang, Y. Deng, J. Q. Lian, P. Du, D. Wei, Y. Zhang, X. X. Sun, L. Gong, and X. Yang, CD147-spike protein is a novel route for SARS-CoV-2 infection to host cells, Signal Transduction Targeted Ther., 2020, 5, 1-10.

8 J. A. Aguiar, B. J. Tremblay, M. J. Mansfield, O. Woody, B. Lobb, A. Banerjee, A. Chandiramohan, N. Tiessen, Q. Cao, A. Dvorkin-Gheva, S. Revill and M. S. Miller, Gene expression and in situ protein profiling of candidate SARS-CoV-2 receptors in human airway epithelial cells and lung tissue, Eur. Respir. J., 2020, 56, 2001123.

9 Q. J. Quinones, G. G. D. Ridder and S. V. Pizzo, GRP78: A chaperone with diverse roles beyond the endoplasmic reticulum, Histol. Histopathol., 2020, 23, 1409-1416.

10 I. M. Ibrahim, D. H. Abdelmalek and A. A. Elfiky, GRP78: A cell's response to stress, Life Sci., 2019, 226, $156-163$.

11 I. M. Ibrahim, D. H. Abdelmalek, M. E. Elshahat and A. A. Elfiky, COVID-19 spike-host cell receptor GRP78 binding site prediction, J. Infect., 2020, 80, 554-562.

12 J. Shang, Y. Wan, C. Luo, G. Ye, Q. Geng, A. Auerbach and F. Li, Cell entry mechanisms of SARS-CoV-2, Proc. Natl. Acad. Sci. U.S.A., 2020, 117, 11727-34.

13 L. Cantuti-Castelvetri, R. Ojha, L. D. Pedro, M. Djannatian, J. Franz, S. Kuivanen, F. van der Meer, K. Kallio, T. Kaya, M. Anastasina and T. Smura, Neuropilin-1 facilitates SARS-CoV-2 cell entry and infectivity, Science, 2020, 13, 856-60.

14 J. L. Daly, B. Simonetti, K. Klein, K. Chen, M. K. Williamson, C. Antón-Plágaro, D. Shoemark, L. SimónGracia, M. Bauer, R. Hollandi, U. F. Greber, P. Horvath, R. B. Session, A. Helenius, J. A. Hiscox, T. Teesalu, D. A. Matthews, A. D. Davidson, B. M. Collins, P. J. Cullen, Y. Yamauchi, Neuropilin-1 is a host factor for SARS-CoV-2 infection, Science, 2020, 370, 861-865.

15 K. D. Seed, Battling phages: how bacteria defend against viral attack, PLOS Pathog., 2015, 11, e1004847. 
16 L. S. Mulwa and M., Stadler, Antiviral compounds from Myxobacteria. Microorganisms, 2018, 6, 73-88.

17 K. I. Mohr, Diversity of Myxobacteria-we only see the tip of the iceberg. Microorganisms, $2018,6,84$.

18 L. S. Mulwa and M. Stadler, Antiviral compounds from Myxobacteria. Microorganisms, 2018, 6, 73-88.

19 J. Herrmann, S. Hüttel and R. Müller, Discovery and biological activity of new chondramides from Chondromyces sp. ChemBioChem, 2014, 14, 1573-1580.

20 M. D. Hanwell, D. E. Curtis, D. C. Lonie, T. Vandermeersch, E. Zurek and G. R. Hutchison, Avogadro: an advanced semantic chemical editor, visualization, and analysis platform, J. Cheminf., 2012, 4, 17.

21 J. Lan, J. Ge, J. Yu, S. Shan, H. Zhou, S. Fan, Q. Zhang, X. Shi, Q. Wang, L. Zhang, X. Wang, Structure of the SARS-CoV-2 spike receptor-binding domain bound to the ACE2 receptor, Nature, 2020, 581, 215-220.

22 E. F. Pettersen, T. D. Goddard, C. C. Huang, G. S. Couch, D. M. Greenblatt, E. C. Meng and T. E. Ferrin, UCSF Chimera - a visualization system for exploratory research and analysis, J. Comput. Chem., 2004, 25, $1605-1612$.

23 M. V. Shapovalov and R. L. Dunbrack, A smoothed backbone-dependent rotamer library for proteins derived from adaptive kernel density estimates and regressions. Structure. 2011, 19, 844-858.

24 A. C. Walls, Y. J. Park, M. A. Tortorici, A. Wall, A. T. McGuire, D. Veesler, Structure, function, and antigenicity of the SARS-CoV-2 spike glycoprotein, Cell, 2020, 181, 281-292.e6.

25 Z. Yang, K. Lasker, D. Schneidman-Duhovny, B. Webb, C. C. Huang, E. F. Pettersen, T. D. Goddard, E. C. Meng, A. Sali and T. E. Ferrin, UCSF Chimera, MODELLER, and IMP: An integrated modeling system. $J$ Struct Biol. 2012, 179. 269-278.

26 K. E. Wright, K. A. Hjerrild, J. Bartlett, A. D. Douglas, J. Jin, R. E. Brown, J. J. Illingworth, R. Ashfield, S. B. Clemmensen, W. A. de Jongh, S. J. Draper and M. K. Higgins, Structure of malaria invasion protein RH5 with erythrocyte basigin and blocking antibodies, Nature, 2014, 515, 427-430.

27 J. Yang, M. Nune, Y. Zong, L. Zhou and Q. Liu, Close and allosteric opening of the polypeptide-binding site in a human Hsp70 chaperone BiP, Structure, 2015, 23, 2191-2203.

28 J. Wang, W. Wang, P. A. Kollman and D. A. Case, Automatic atom type and bond type perception in molecular mechanical calculations, J. Mol. Graphics Modell., 2006, 25, 247-260.

29 J. Yang, A. Roy and Y. Zhang, Protein-ligand binding site recognition using complementary binding-specific substructure comparison and sequence profile alignment, Bioinformatics, 2013, 29, 2588-2595.

30 O. Trott, A. J. Olson, AutoDock Vina: improving the speed and accuracy of docking with a new scoring function, efficient optimization and multithreading, J. Comput. Chem., 2010, 31, 455-461.

31 BIOVIA, Dassault Systèmes, BIOVIA Discovery Studios (Version 4.1), Dassault Systèmes, San Diego, CA, 2020.

32 E. F. Pettersen, T. D. Goddard, C. C. Huang, E. C. Meng, G. S. Couch, T. T. Croll, J. H. Morris and T. E. Ferrin, UCSF ChimeraX: Structure visualization for researchers, educators, and developers, Protein Sci., 2021, 30, 70-82. 
33 G. C. Van Zundert, J. P. Rodrigues, M. Trellet, C. Schmitz, P. L. Kastritis, E. Karaca, A. S. Melquiond, M. van Dijk, S. J. De Vries and A. M. Bonvin, The HADDOCK2. 2 web server: user-friendly integrative modeling of biomolecular complexes, J. Mol. Biol., 2016, 428, 720-725.

34 A. Daina, O. Michielin and V. Zoete, Swiss ADME: a free web tool to evaluate pharmacokinetics, druglikeness and medicinal chemistry friendliness of small molecules. Sci. Rep., 2017, 7, 42717.

35 A. P. G. Macabeo, L. A. E. Pilapil, K. Y. M. Garcia, M. T. J. Quimque, C. Phukhamsakda, A. J. C. Cruz, K. D. Hyde and M. Stadler, Alpha-glucosidase-and lipase-inhibitory phenalenones from a new species of Pseudolophiostoma originating from Thailand, Molecules, 2020, 25, 965.

36 C. Phukhamsakda, A. P. G. Macabeo, K. T. Yuyama, K. D. Hyde, and M. Stadler, Biofilm inhibitory abscisic acid derivatives from the plant-associated dothideomycete fungus, Roussoella sp. Molecules, 2018, 23, 2190.

37 R. Escobedo-González, C. L. Vargas-Requena, E. Moyers-Montoya, J. M. Aceves-Hernández, M. I. NicolásVázquez and R. Miranda-Ruvalcaba, In silico study of the pharmacologic properties and cytotoxicity pathways in cancer cells of various indolylquinone analogues of perezone, Molecules, 2017, 22, 1060.

38 Q. Wang, Y. Zhang, L. Wu, S. Niu, C. Song, Z. Zhang, G. Lu, C. Qiao, Y. Hu, K. Y. Yuen, Q. Wang, H. Zhou, J. Yan and J. Qi, Structural and Functional Basis of SARS-CoV-2 entry by using human ACE2, Cell, 2020, 181, 894-904.e9

39 E. Laurini, D. Marson, S. Aulic, M. Fermeglia and S. Pricl, Computational alanine scanning and structural analysis of the SARS-CoV-2 spike protein/angiotensin-converting enzyme 2 complex, ACS Nano, 2020, 14, 11821-11830.

40 H. Othman, Z. Bouslama, J. T. Brandenburg, J. da Rocha, Y. Hamdi, K. Ghedira, N. Srairi-Abid and S. Hazelhurst, Interaction of the spike protein RBD from SARS-CoV-2 with ACE2: similarity with SARS-CoV, hot-spot analysis and effect of the receptor polymorphism, Biochem. Biophys. Res. Commun., 2020, 30, 702708 .

41 Y. He, J. Li and S. A. Jiang, A single amino acid substitution (R441A) in the receptor-binding domain of SARS coronavirus spike protein disrupts the antigenic structure and binding activity, Biochem. Biophys. Res Commun., 2006, 344, 106-113.

42 O. W. Ng, C. T. Keng, C. S. Leung, J. S. Peiris, L. L. Poon and Y. J. Tan, Substitution at aspartic acid 1128 in the SARS coronavirus spike glycoprotein mediates escape from a S2 domain-targeting neutralizing monoclonal antibody, PLoS One, 2014, 9, e102415.

43 B. Korber, W. M. Fischer, S. Gnanakaran, H. Yoon, J. Theiler, W. Abfalterer, N. Hengartner, E. E. Giorgi, T. Bhattacharya, B. Foley, K. M. Hastie, M. D. Parker, D. G. Partridge, C. M. Evans, T. M. Freeman, T. I. de Silva, Sheffield COVID-19 Genomics Group, C. McDanal, L. G. Perez, H. Tang, A. Moon-Walker, S. P. Whelan, C. C. LaBranche, E. O. Saphire and D. C. Montefiori, Tracking changes in SARS-CoV-2 spike: Evidence that D614G increases infectivity of the COVID-19 virus, Cell, 2020, 182, 812-827.e19.

44 A. Fernández, Structural impact of mutation D614G in SARS-CoV-2 spike protein: enhanced infectivity and therapeutic opportunity, ACS Med. Chem. Lett., 2020, 11, 1667-1670. 
45 M. Becerra-Flores and T. Cardozo, SARS-CoV-2 viral spike G614 mutation exhibits higher case fatality rate, Int. J. Clin. Pract., 2020, 74, e13525.

46 Q. Li, J. Wu, J. Nie, L. Zhang, H. Hao, S. Liu, C. Zhao, Q. Zhang, H. Liu, L. Nie, H. Qin, M. Wang, Q. Lu, X. Li, Q. Sun, J. Liu, L. Zhang, X. Li, W. Huang and Y. Wang. The impact of mutations in SARS-CoV-2 spike on viral infectivity and antigenicity, Cell, 2020, 182, 1284-1294.e9.

47 J. Chen, R. Wang, M. Wang and G. W. Wei, Mutations strengthened SARS-CoV-2 infectivity, J. Mol. Biol., 2020, 432, 5212-5226.

48 Preliminary genomic characterisation of an emergent SARS-CoV-2 lineage in the UK defined by a novel set of spike mutations, https://virological.org/t/preliminary-genomic-characterisation-of-an-emergent-sars-cov2-lineage-in-the-uk-defined-by-a-novel-set-of-spike-mutations/563, (accessed December 2020).

49 J. Wise., Covid-19: New coronavirus variant is identified in UK, Br. Med. J., 2020, 371, m4857.

50 A. J. Greaney, A. N. Loes, K. H. Crawford, T. N. Starr, K. D. Malone, H. Y. Chu and J. D. Bloom, Comprehensive mapping of mutations to the SARS-CoV-2 receptor-binding domain that affect recognition by polyclonal human serum antibodies, bioRxiv, 2020, preprint, DOI: 10.1101/2020.12.31.425021.

51 C. M. Voloch, F. Ronaldo da Silva, L. G. de Almeida, C. C. Cardoso, O. J. Brustolini, A. L. Gerber, A. P. de C Guimarães, D. Mariani, R. M. da Costa, O. C. Ferreira and C. U. Workgroup, Genomic characterization of a novel SARS-CoV-2 lineage from Rio de Janeiro, Brazil, medRxiv, 2020, preprint, DOI: 10.1101/2020.12.23.20248598.

52 Y. Weisblum, F. Schmidt, F. Zhang, J. DaSilva, D. Poston, J. C. Lorenzi, F. Muecksch, M. Rutkowska, H. H. Hoffmann, E. Michailidis, C. Gaebler, M. Agudelo, A. Cho, Z. Wang, A. Gazumyan, M. Cipolla, L. Luchsinger, C. D. Hillyer, M. Caskey, D. F. Robbiani, C. M. Rice, M. C. Nussenzweig, T. Hatziioannou and P. D. Bieniasz, Escape from neutralizing antibodies by SARS-CoV-2 spike protein variants, Elife, 2020, 9 , e61312.

53 T. Muramatsu, Basigin (CD147), a multifunctional transmembrane glycoprotein with various binding partners, J. Biochem., 2016, 159, 481-90.

54 T. Chen, D. Wu, H. Chen, W. Yan, D. Yang, G. Chen, K. Ma, D. Xu, H. Yu, H. Wang, T. Wang, W. Guo, J. Chen, C. Ding, X. Zhang, J. Huang, M. Han, S. Li, X. Luo, J. Zhao and Q. Ning, Clinical characteristics of 113 deceased patients with coronavirus disease 2019: retrospective study, BMJ, 2020, 368, m1091.

55 I. Huang and R. Pranata, Lymphopenia in severe coronavirus disease-2019 (COVID-19): systematic review and meta-analysis, J. Intensive Care, 2020, 8, 36.

56 J. Liu, H. Li, M. Luo, J. Liu, L. Wu, X. Lin, R. Li, Z. Wang, H. Zhong, W. Zheng, Y. Zhou, D. Jiang, X. Tan, Z. Zhou, H. Peng and G. Zhang, Lymphopenia predicted illness severity and recovery in patients with COVID-19: A single-center, retrospective study, PLoS One, 2020, 15, e0241659.

57 A. Jafarzadeh, S. Jafarzadeh, P. Nozari, P. Mokhtari and M. Nemati, Lymphopenia an important immunological abnormality in patients with COVID-19: Possible mechanisms, Scand. J. Immunol., 2020, 93, e12967. 
58 Y. Xiong, Y. Liu, L. Cao, D. Wang, M. Guo, A. Jiang, D. Guo, W. Hu, J. Yang, Z. Tang, H. Wu, Y. Lin, M. Zhang, Q. Zhang, M. Shi, Y. Liu, Y. Zhou, K. Lan and Y. Chen, Transcriptomic characteristics of bronchoalveolar lavage fluid and peripheral blood mononuclear cells in COVID-19 patients, Emerg Microbes Infect., 2020, 9, 761-770.

59 M. A. Helal, S. Shouman, A. Abdelwaly, A. O. Elmehrath, M. Essawy, S. M. Sayed, A. H. Saleh and N. ElBadri, Molecular basis of the potential interaction of SARS-CoV-2 spike protein to CD147 in COVID-19 associated-lymphopenia, J. Biomol. Struct. Dyn., 2020, 16, 1-11.

60 U. Radzikowska, M. Ding, G. Tan, D. Zhakparov, Y. Peng, P. Wawrzyniak, M. Wang, S. Li, H. Morita, C. Altunbulakli, M. Reiger, A. U. Neumann, N. Lunjani, C. Traidl-Hoffmann, K. C. Nadeau, L. O'Mahony, C. Akdis and M. Sokolowska, Distribution of ACE2, CD147, CD26, and other SARS-CoV-2 associated molecules in tissues and immune cells in health and in asthma, COPD, obesity, hypertension, and COVID19 risk factors, Allergy, 2020, 75, 2829-2845.

61 R. Sabirli, A. Koseler, T. Goren, I. Turkcuer and O. Kurt, High GRP78 levels in Covid-19 infection: A casecontrol study, Life Sci., 2021, 265, 118781.

62 L. Allam, F. Ghrifi, H. Mohammed, N. El Hafidi, R. El Jaoudi, J. El Harti, B. Lmimouni, L. Belyamani and A. Ibrahimi, Targeting the GRP78-dependent SARS-CoV-2 cell entry by peptides and small molecules, Bioinf. Biol. Insights, 2020, 14, 1-11.

63 A. Palmeira, E. Sousa, A. Köseler, R. Sabirli, T. Gören, İ. Türkçüer, Ö. Kurt, M. M. Pinto and M. H. Vasconcelos, Preliminary virtual screening studies to identify GRP78 inhibitors which may interfere with SARS-CoV-2 infection, Pharmaceuticals, 2020, 13, 132.

64 M. Egbert, A. Whitty, G. M. Keserủ and S. Vajda, Why some targets benefit from beyond rule of five drugs, J. Med. Chem., 2019, 62, 10005-10025. 